DOI 10.46298/jtcam.6753 OAI hal-02925844V4

History

Received Sept 2, 2020 Reviewed Nov 17, 2020 Accepted Jan 6, 2021 Published Mar 10, 2021

Associate Editor Julien Réthoré

Reviewers Anonymous Anonymous

Supplementary Material DOI $10.5281 /$ zenodo. 4467389

Licence

CC BY 4.0 (c)The Authors

\section{Brittle material strength and fracture toughness estimation from four-point bending test}

\author{
๑1 Aurélien Doitrand, Ronan Henry, and @Sylvain Meille \\ Université Lyon, INSA-Lyon, MATEIS UMR CNRS 5510, F-69621 Villeurbanne Cedex, France
}

The failure stress under four-point bending cannot be considered as an intrinsic material property because of the well-known size effect of increasing maximum flexural stress with decreasing specimen size. In this work, four-point bending tests are analyzed with the coupled criterion for different sample sizes. The maximum flexural stress only tends towards the material tensile strength provided the specimen height is large enough as compared to the material characteristic length. In that case, failure is mainly driven by a stress criterion. Failure of smaller specimens is driven both by energy and stress conditions, thus depending on the material tensile strength and fracture toughness. Regardless of the material mechanical properties, we show that the variation of the ratio of maximum flexural stress to strength as a function of the ratio of specimen height to material characteristic length follows a master curve, for which we propose an analytical expression. Based on this relation, we propose a procedure for the post-processing of four-point bending tests that allows the determination of both the material tensile strength and fracture toughness. The procedure is illustrated based on four-point bending experiments on three types of gypsum of different porosity fractions.

Keywords: strength, four-point bending, coupled criterion

\section{Introduction}

Size effect refers to the influence of the characteristic structure dimension on the nominal failure stress. Considering four-point bending as a matter of example, it is usually observed experimentally that the smaller the specimen the larger the maximum flexural stress. An explanation of this size effect relying on the weakest link theory was introduced by Weibull (Weibull 1939; Weibull 1949; Weibull 1951), based on the idea that failure is driven by flaws inside the materials and that the larger the specimen, the larger the probability for a large flaw to exist in the specimen. This approach was later on justified based on statistical distribution of microscopic flaws. It is used for describing the size effect in the fracture of brittle solids (Bermejo and Danzer 2014). However, it also suffers from some drawbacks since various tests revealed either a stronger (Bažant and Planas 1998) or weaker (Lu et al. 2004) size effects than predicted by Weibull theory. Another objection to this purely statistical approach is that it does not contain any material characteristic length (Bažant 1999).

To avoid this limitation, the idea of combining the theory of plasticity (characterized by the material strength $\sigma_{c}$ or yield limit) and Linear Elastic Fracture Mechanics (LEFM, characterized by the fracture energy $\mathcal{G}_{c}$ ) was proposed. While both approaches do not contain any characteristic length, their combination does through the material characteristic length $E \mathcal{G}_{c} / \sigma_{c}^{2}$, where $E$ is the material Young's modulus. This idea led to the possibility of a deterministic size effect, extensively studied by Bažant (1999); Bažant (1984); Bažant and Pfeiffer (1987); Bažant and Xi (1991), that could be an alternative explanation to the statistical size effect.

LEFM is mainly limited by the basic assumption of a pre-existing crack preventing the assessment of crack initiation. To overcome this drawback, the coupled criterion (CC) was developed by Leguillon (2002) in order to study crack initiation (Weißgraeber et al. 2016). It is basically founded on the simultaneous fulfillment of both energy and stress conditions. Coupling 
these two conditions allows the determination of the material characteristic length and thus reproducing deterministic size effects. A tool for the finite element implementation of the CC has recently been developed (Doitrand et al. 2020c).

Crack initiation in laminates (Parvizi et al. 1978) was the first example of size effect assessed with the CC (Leguillon 2002), which was also studied by García et al. (2016); García et al. (2018); García et al. (2019) in 3D, accounting for residual stresses or comparing the CC with other criteria. The size effect assessment by the CC offered an alternative explanation to the statistical approach. Later on, Leguillon et al. (2015) combined the CC and Weibull statistics in order to account for both deterministic and statistical size effects. They also pointed out that according to the CC, the tensile strength can be considered as a material parameter, contrary to the flexural strength which depends on the specimen size. Cornetti et al. (2006) studied size effect under three point bending and highlighted the ability of the $\mathrm{CC}$ to reproduce the experimentally observed size effect and capture the concave-convex transition in log-log plot of flexural stress as a function of specimen size when passing from un-notched to notched specimen. Size effect of the notch radius on the initiation loading at blunt notches under pure opening mode was studied by Leguillon et al. (2007) and Carpinteri et al. (2011) using either the classical stress criterion (Leguillon et al. 2007) or its averaged version (Carpinteri et al. 2011). Size effect on the failure stress in notched structures under mixed mode was studied by Cornetti et al. (2013), considering either self-similar specimens containing a re-entrant cornered hole or square holed configuration undergoing various mixed mode loading configurations. The CC also allows the study of the size effect of specimens containing a hole (Leguillon et al. 2007; Cornetti et al. 2013; Doitrand et al. 2019; Doitrand and Sapora 2020; Martin et al. 2012; Cornetti and Sapora 2019). The influence of flaw size in ceramics under tensile loading was assessed by Leguillon et al. (2018) and Martin et al. (2018), showing a transition between a constant to decreasing apparent tensile strength depending on the flaw size relative to the material characteristic length.

Size effect is particularly marked in case of small-scale specimen testing. Indeed, the smaller the specimen, the smaller the energy available for crack initiation and thus the larger the loading required to fulfill the energy condition necessary for crack initiation, which may result in large local stress levels compared to the material tensile strength. For instance, stresses up to $5 \mathrm{GPa}$ are locally reached in micron-scale alumina platelets under three-point bending (Feilden et al. 2017), the material exhibiting $\mathrm{a} \approx 1 \mathrm{GPa}$ tensile strength considering the $\mathrm{CC}$. The application of the $\mathrm{CC}$ allows a correct prediction of the failure force and demonstrates that in such configuration, failure is driven by the energy condition involving the platelet fracture toughness (Doitrand et al. 2020a). The efficiency of the $\mathrm{CC}$ to predict crack initiation at small-scale was also recently illustrated on silicon nanoscale cantilevers (Gallo and Sapora 2020) and $\mathrm{UO}_{2}$ micro-cantilevers loaded in flexion (Doitrand et al. 202ob).

This work is focused on size effect in four-point bending samples without notch, studied experimentally by tests on gypsum and assessed numerically using the CC. The objective of the paper is to establish a relation between the maximum flexural stress at failure (calculated from the measured failure force), the specimen dimensions and the material properties, namely Young's modulus, fracture toughness and tensile strength.

Section 2 is dedicated to the experimental characterization of gypsum specimens: manufacturing and testing under four-point bending. In Section 3 we present the CC for crack initiation modeling. In Section 4, we use the CC to assess numerically the size effect, which allows us to establish a relation between the maximum stress locally reached, the specimen size and material parameters in Section 5 . We thus propose a post-processing approach for the determination of $\mathcal{G}_{c}$ and $\sigma_{c}$ based on four-point bending experiments.

\section{Experiments}

The material under investigation is gypsum. We study three shades of gypsum: $\alpha$-gypsum, $\beta$-gypsum and a dental gypsum referred to as $\gamma$-gypsum in the following. The main difference between these three shades is their pore fraction and density, their properties are given in Table 1.

Manufacturing of samples is made by manually mixing hemihydrate powders with tap water at $23{ }^{\circ} \mathrm{C}$. Depending on the powder type, the amount of water varies, leading to different final 


$\begin{array}{lcccccc}\text { Material } & \begin{array}{c}\text { pore } \\ \text { fraction }\end{array} & \begin{array}{c}\text { density } \\ \rho\left(\mathrm{g} / \mathrm{cm}^{3}\right)\end{array} & \begin{array}{c}\text { Young's modulus } \\ E(\mathrm{GPa})\end{array} & \begin{array}{c}\text { Poisson's } \\ \text { ratio, } v\end{array} & \begin{array}{c}\text { tensile stress } \\ \sigma_{c}(\mathrm{MPa})\end{array} & \begin{array}{c}\text { critical SIF } \\ K_{I c}\left(\mathrm{MPa} \cdot \mathrm{m}^{1 / 2}\right)\end{array} \\ \gamma \text {-gypsum } & 0.15 & 1.94 \pm 0.03 & 38 \pm 1 & 0.21 & 12 \pm 2 & 0.4 \pm 0.05 \\ \alpha \text {-gypsum } & 0.30 & 1.59 \pm 0.03 & 16 \pm 0.5 & 0.21 & 9.5 \pm 1.5 & 0.35 \pm 0.03 \\ \beta \text {-gypsum } & 0.50 & 1.03 \pm 0.03 & 3.8 \pm 0.5 & 0.21 & 2.7 \pm 1 & 0.1 \pm 0.03\end{array}$

Table 1 Material properties of $\alpha$-, $\beta$ - and $\gamma$-gypsum (Meille and Garboczi 2001; Meille 2001; Sanahuja et al. 2010).

porosity fraction. $\gamma, \alpha$ and $\beta$ samples are made from a type 4 dental gypsum (Fujirock), Prestia model (Lafarge) and a powder supplied in a store retail respectively. The specimens exhibit typical interconnected pores between the gypsum crystals of the micrometer size as well as some macropores (Adrien et al. 2016). The macropores are not likely to be connected since they originate from entrapped air in the hemihydrate powder before mixing (Meille 2001; Adrien et al. 2016). The purity of the powders is larger than $96 \%$. The impurities mainly consist of calcium carbonate micron-size grains (Meille 2001). Young's modulus has been determined with ultrasonic method (Grindo-sonic) and Poisson's ratio is estimated for porous gypsum as shown in (Meille and Garboczi 2001; Sanahuja et al. 2010).

It can be observed that the Young's modulus is strongly dependent on pore fraction. Similar relations can be found for the tensile strength $\sigma_{c}$ and critical stress intensity factor (SIF) $K_{I c}$. The tensile strength $\sigma_{c}$ and critical stress intensity factor $K_{I c}$ were determined experimentally ( $\alpha$ - and $\beta$-gypsum) and estimated ( $\gamma$-gypsum) based on the gypsum pore fraction (Meille and Garboczi 2001; Sanahuja et al. 2010; Meille 2001).

Several specimens of each gypsum shade are tested under four-point bending. The material exhibits a linear elastic behavior until brittle failure. Different specimen heights are used in order to assess a possible size effect. Accordingly, two bending apparatus (with $\left(L_{\mathrm{span}}=90.5 \mathrm{~mm}\right.$, $\left.\ell_{\text {span }}=30 \mathrm{~mm}\right)$ and $\left(L_{\text {span }}=35 \mathrm{~mm}, \ell_{\text {span }}=10 \mathrm{~mm}\right)$ lower and upper spans distance respectively) have been used depending on the specimen height. The specimen dimensions are given in Appendix in Table A.1 ( $\alpha$-gypsum), Table A.2 ( $\beta$-gypsum) and Table A.3 ( $\gamma$-gypsum) together with the failure force $F_{c}$ and the corresponding maximum flexural stress $\sigma_{\max }$, calculated as:

$$
\sigma_{\max }=\frac{3}{2} \frac{F_{c}\left(L_{\text {span }}-\ell_{\text {span }}\right)}{t h^{2}},
$$

where $t$ is the specimen thickness and $h$, the specimen height.

The specimen dimensions are depicted in Figure 1. A size effect can be observed since the maximum flexural stress measured experimentally increases with decreasing specimen height.

Figure 1 Four-point bending specimen dimensions.

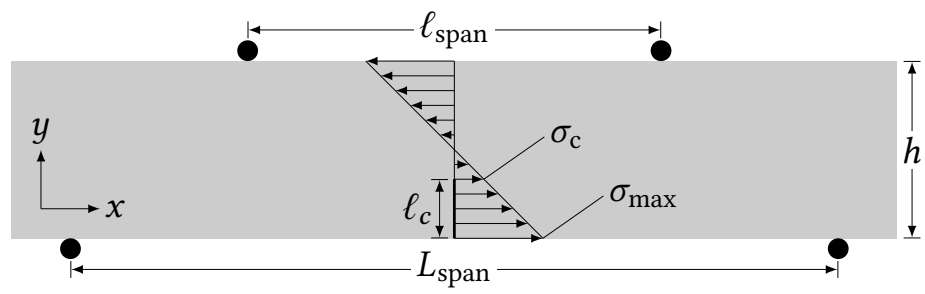

As mentioned in (Leguillon et al. 2015), the maximum flexural stress (or flexural strength) cannot therefore be considered as an intrinsic material property. It can also be noted that for a given specimen height, a statistical scattering is observed which is linked to the presence of macropores acting as critical flaws (Sanahuja et al. 2010). Indeed, stress concentrations are induced at the macropore vicinity, which may thus be privileged crack initiation locations. Therefore, provided the macropore is located sufficiently close to the specimen face under tension, crack initiation at the macropore may be more likely than crack initiation at the specimen free edge. It also depends on the pore size as shown for instance in (Leguillon et al. 2007).

The objective of this work is to assess numerically the size effect and provide a post-processing approach establishing a link between the measured specimen dimensions and maximum flexural stress ( $h$ and $\sigma_{\max }$ ) and the material properties (tensile strength $\sigma_{c}$ and critical stress intensity factor $K_{I c}$ or fracture toughness $\mathcal{G}_{c}$ ). 


\section{The coupled criterion}

The CC aims at predicting crack initiation by combining stress and energy conditions. It states that crack nucleation requires, on the one hand, that the stress just before crack initiation exceeds the tensile strength over the whole crack path, and on the other hand, that a sufficient amount of energy is dissipated by crack initiation. The energy condition reverts to comparing the potential energy released by crack initiation $-\Delta W=W(0)-W(\ell)$, where $\ell$ is the crack length and $W$ the potential energy, to the energy required for crack initiation $\mathcal{G}_{c} \ell$, where $\mathcal{G}_{c}$ is the material fracture toughness. Coupling both conditions consists in determining the initiation displacement $U_{0}=U_{c}$ and the corresponding initiation crack length $\ell_{c}$ that simultaneously satisfy both conditions, which can thus be written as follows ( $y=0$ corresponds to the specimen mid-height, $c f$. Figure 1)

$$
\left\{\begin{array}{l}
\sigma\left(y=-h+\ell, U_{c}\right) \geqslant \sigma_{c}, \quad \forall \ell \leqslant \ell_{c}, \\
G_{\text {inc }}\left(\ell_{c}, U_{c}\right)=-\Delta W\left(\ell_{c}\right) / \ell_{c}=\mathcal{G}_{c} .
\end{array}\right.
$$

Solving the CC reverts to the determination of the minimum imposed loading $U_{c}$ for which both criteria are simultaneously fulfilled. The corresponding crack length $\ell_{c}$ is the initiation crack length. It requires the calculation of the potential energy release as a function of the crack length $-\Delta W=W(0)-W(\ell)$. This quantity is obtained by means of Finite Element (FE) calculations, successively unbuttoning nodes along the predefined crack path. The calculation allowing the determination of $W(0)$ corresponds to a configuration without a crack, which also enables to calculate the stress variation along the crack path before crack initiation. Note that the stress variation could also be obtained analytically using beam theory provided the specimen dimensions verifies the corresponding hypotheses. 2D plane strain linear elastic FE calculations are set-up employing Abaqus ${ }^{\mathrm{TM}}$. Since the stress fields are homogeneous within the specimen thickness, the 2D analysis is expected to provide results close to $3 \mathrm{D}$ analysis. The boundary conditions consist in imposed displacements at the spans and support locations. The mesh is refined in the vicinity of the crack initiation location. The minimum mesh size is set to $\ell_{\text {mat }} / 100$, where $\ell_{\text {mat }}=E^{\prime} \mathcal{G}_{c} / \sigma_{c}^{2}$ with $E^{\prime}=E /\left(1-v^{2}\right)$ is the material characteristic length.

The stress distribution is a linear function of the position along the specimen height that varies from $-\sigma_{\max }$ to $\sigma_{\max }, \sigma_{\max }$ being the maximum flexural stress, therefore the stress conditions gives a relation between the maximum flexural stress to strength ratio and the initiation length to specimen height ratio

$$
\frac{\sigma_{\max }}{\sigma_{c}}=\frac{1}{1-2 \ell_{c} / h} .
$$

The initiation $\ell_{c}$ is not known a priori and depends both on the material properties and specimen geometry but can be determined using the CC. The incremental energy release rate is a monotonic increasing function of the crack length and tends to zero when the crack size tends towards zero. Figure 2(a) shows a graphical representation of the CC solution including the stress (dashed line) and the energy (thick solid line) criteria for i) a too small imposed displacement (dashed line) and ii) an imposed displacement corresponding to the initiation displacement (plain lines). The stress criterion is fulfilled for all the lengths for which $\sigma / \sigma_{c} \geqslant 1$. Therefore, for a given imposed displacement $U_{0}$, it yields an upper bound for the admissible initiation crack lengths. Similarly, the energy criterion is fulfilled for all the lengths for which $G_{\text {inc }} / \mathcal{G}_{c} \geqslant 1$. It thus provides a lower bound for the admissible initiation crack lengths for a given imposed displacement. For a too small imposed displacement $\left(U_{0}<U_{c}\right)$, it can be seen that both the stress and the energy criteria are satisfied for two non-intersecting ranges of crack lengths (the upper bound given by the stress criterion is smaller than the lower bound given by the energy criterion). Increasing the imposed displacement allows us to increase the upper bound given by the stress criterion and decreasing the lower bound given by the energy criterion until they match for an imposed displacement $U_{0}=U_{c}$. It enables to determine the crack length for which both criteria are simultaneously fulfilled, i.e. the initiation crack length (black circle in Figure 2).

In most of cases, crack initiation is driven by both criteria and thus depends on both $\mathcal{G}_{c}$ and $\sigma_{c}$ (Figure 2(a)). Special configurations may also arise for which one of the two criteria is dominant. For instance, the stress criterion may be dominant if the initiation length is very small 

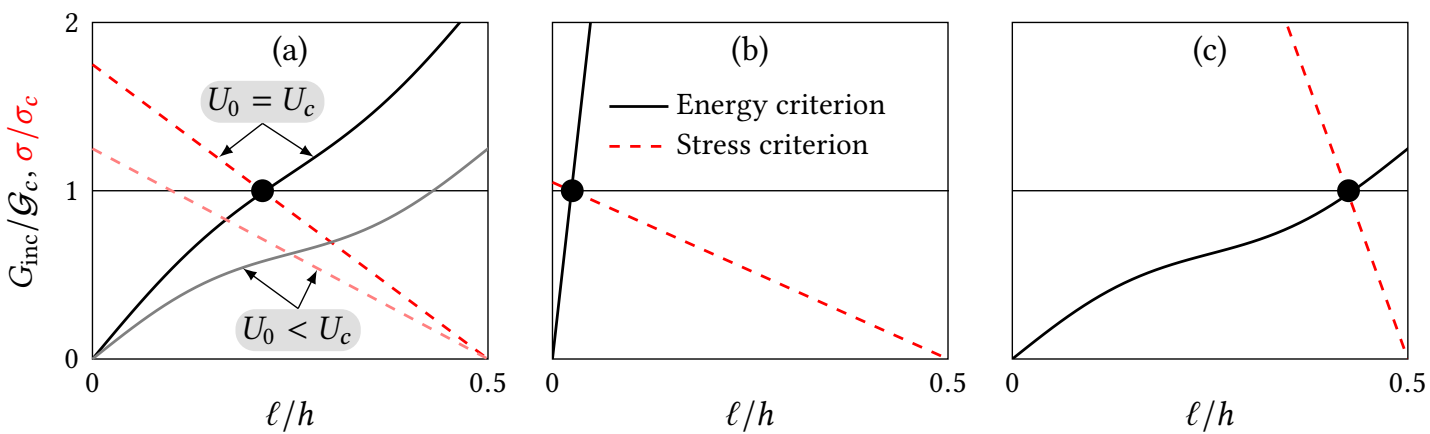

Figure 2 Stress to strength (stress criterion) and incremental energy release rate to fracture toughness (energy criterion) ratios as a function of crack length to specimen height ratio. (a) Classical case, (b) dominating stress criterion (small initiation length to specimen height ratio) and (c) dominating energy criterion (initiation length to specimen height ratio close to 0.5 ).

compared to the specimen height (Figure $2(\mathrm{~b})$ ), therefore the maximum flexural stress is close to the material tensile strength $\left(\ell_{c} \ll h \Rightarrow \sigma_{\max } \approx \sigma_{c}\right)$. Since the initiation length is a fraction of the material characteristic length $\ell_{\text {mat }}$ (Martin et al. 2018), this situation is expected for large specimens. On the contrary, the energy criterion may be dominant for initiation length close to half the specimen height (Figure 2(c)), the stress criterion being almost fulfilled over the whole area undergoing traction. This situation is rather expected for small specimens.

The CC allows us to compute the initiation length $\ell_{c}$ and the imposed displacement $U_{c}$ from which the failure force and corresponding failure stress are obtained by means of finite element calculations. Therefore, for given specimen geometry $(h)$ and material properties $\left(E, v, \mathcal{G}_{c}, \sigma_{c}\right)$, the $\mathrm{CC}$ allows us to calculate the corresponding maximum flexural stress $\sigma_{\max }$, which is exploited in next section in order to assess the size effect.

\section{Size effect}

In this section, we study the deterministic size effect related to the interaction between the initiation length predicted by the $\mathrm{CC}$ and the dimensions of the sample. It is not related to any statistical distribution of defects.

\subsection{Size effect for given material properties}

We first consider material properties representative of $\alpha$-gypsum, i.e. $E=16 \mathrm{GPa}, v=0.21, \mathcal{G}_{c}=$ $7.3 \mathrm{~J} / \mathrm{m}^{2}$ and $\sigma_{c}=9.5 \mathrm{MPa}$. The corresponding material characteristic length is $\ell_{\mathrm{mat}}=1.36 \mathrm{~mm}$. The CC is used to predict failure of specimens with different heights from $0.1 \ell_{\text {mat }}$ to $90 \ell_{\text {mat }}$. Figure 3 shows the initiation length (normalized by the material characteristic length - Figure 3 (a) - or by the specimen height - Figure $3(b))$ as a function of the ratio of the specimen height to material characteristic length $h / \ell_{\text {mat }}$.

It can be observed first that for specimen with a large height relatively to the material characteristic length $\left(h / \ell_{\text {mat }} \geqslant 20\right)$, the initiation length reaches a plateau and is independent of the specimen size, typically leading to a situation for which failure is driven by the stress criterion (see Figure 3(a)). When decreasing the specimen height, the initiation length also decreases whereas the ratio of initiation length to specimen height $\ell_{c} / h$ increases. When $h \rightarrow 0, \ell_{c} / h \rightarrow 0.5$ so that the energy criterion becomes more and more dominant (see Figure $3(\mathrm{a})$ ). The classical situation involving both criteria is encountered for intermediate ratios of specimen height to material characteristic length. Therefore, the initiation length to specimen height ratio decreases from 0.5 to zero with increasing specimen height (see Figure $3(\mathrm{~b})$ ). Since the stress variation is linear as a function of the position along the specimen height and since crack initiation ensures that $\sigma\left(\ell_{c}\right)=\sigma_{c}$, it yields that the maximum flexural stress increases with decreasing specimen size. Figure 4 shows the increase in the maximum flexural stress as a function of $h / \ell_{\text {mat }}$, hence reproducing qualitatively the size effect observed experimentally.

For large enough specimen height $\left(h / \ell_{\text {mat }}>20\right)$, the theoretical difference between the maximum flexural stress $\sigma_{\max }$ and the material tensile strength $\sigma_{c}$ is smaller than $5 \%$. For this 

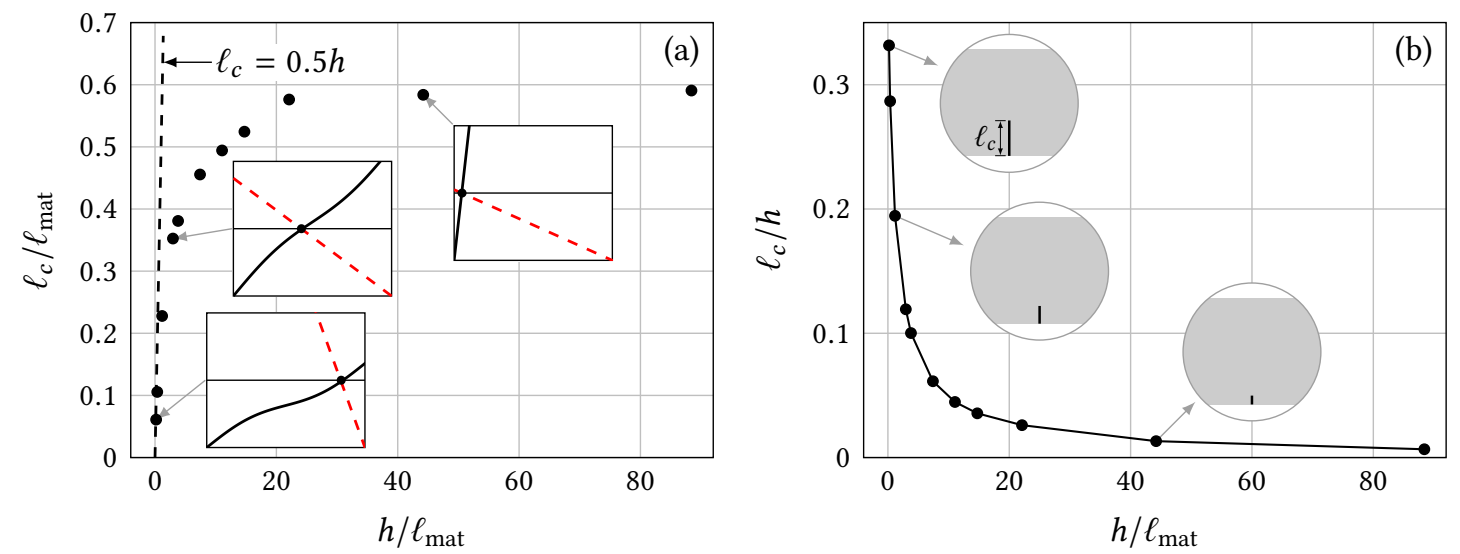

Figure 3 (a) Initiation crack length to material characteristic length ratio as a function of specimen height to material characteristic length ratio. The insets show the CC in the form of stress to strength (dashed line) and incremental energy release rate to fracture toughness (thick solid line) ratios. (b) Initiation crack length to specimen height ratio as a function of specimen height to material characteristic length ratio. The insets depict the size of the initiation length $\ell_{c}$ compared to the specimen height $h$.

Figure 4 Maximum flexural stress to strength ratio as a function of specimen height to material characteristic length ratio. The insets depict the stress gradient along the specimen height as well as the initiation length $\ell_{c}$ for which $\sigma\left(\ell_{c}\right)=\sigma_{c}$.

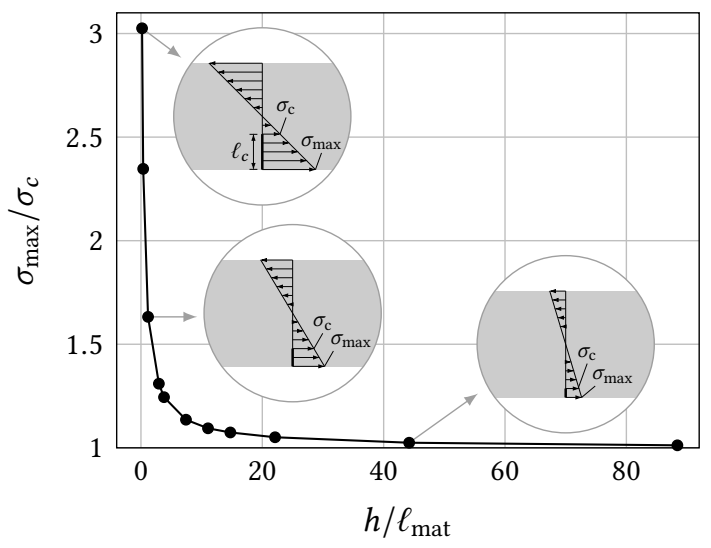

range of $h / \ell_{\text {mat }}$, the flexural strength measurement should thus provide a good estimate of the tensile strength, which is not the case for smaller specimen height to material characteristic length ratios.

\subsection{Influence of material properties on size effect}

We now investigate the influence of the material fracture properties $\left(\sigma_{c}, \mathcal{G}_{c}\right)$ on the observed size effect. We consider seven fracture parameter couples given in Table 2 corresponding to four different $\ell_{\text {mat }}$.

$\begin{array}{lccccccc}\text { Property } & \#_{1} & \#_{2} & \#_{3} & \#_{4} & \#_{5} & \# 6 & \#_{7} \\ \sigma_{c}(\mathrm{MPa}) & 9.5 & 9.5 & 6.72 & 9.5 & 4.25 & 9.5 & 13.4 \\ \mathcal{G}_{c}\left(\mathrm{~J} / \mathrm{m}^{2}\right) & 7.3 & 14.6 & 7.3 & 36.6 & 7.3 & 3.65 & 7.3 \\ \ell_{\text {mat }}(\mathrm{mm}) & 1.36 & 2.72 & 2.72 & 6.79 & 6.79 & 0.68 & 0.68\end{array}$

Table 2 Strength and toughness couples leading to four different material characteristic lengths.

Figure 5 shows the initiation length to material characteristic length ratio as a function of the specimen height obtained using the CC for the different fracture parameter couples. First, it can be observed that the same variation is obtained for material parameters giving a similar value of $\ell_{\text {mat }}$ (symbols are superimposed in Figure 5). The increase in initiation length as a function of the specimen height until a plateau for sufficiently large specimen height is observed for all the studied fracture parameter couples. Besides, the initiation length at the plateau is an increasing function of the material characteristic length, as shown in the inset of Figure 5 .

Figure 6 shows the initiation length to specimen height ratio as a function of either the 


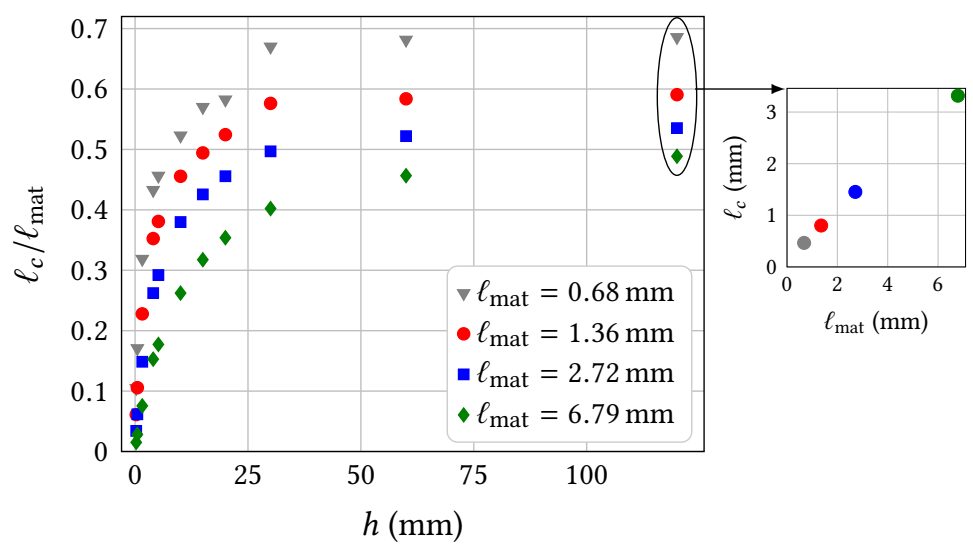

Figure 5 Initiation crack length to characteristic material length ratio as a function of the specimen size for various $\left(\mathcal{G}_{c}, \sigma_{c}\right)$ couples corresponding to different material characteristic lengths $\ell_{\text {mat }}$. The inset depicts the initiation length for the largest specimen as a function of the material characteristic length.

specimen height, in Figure 6(a), or the specimen height to material characteristic length ratio, in Figure 6(b).
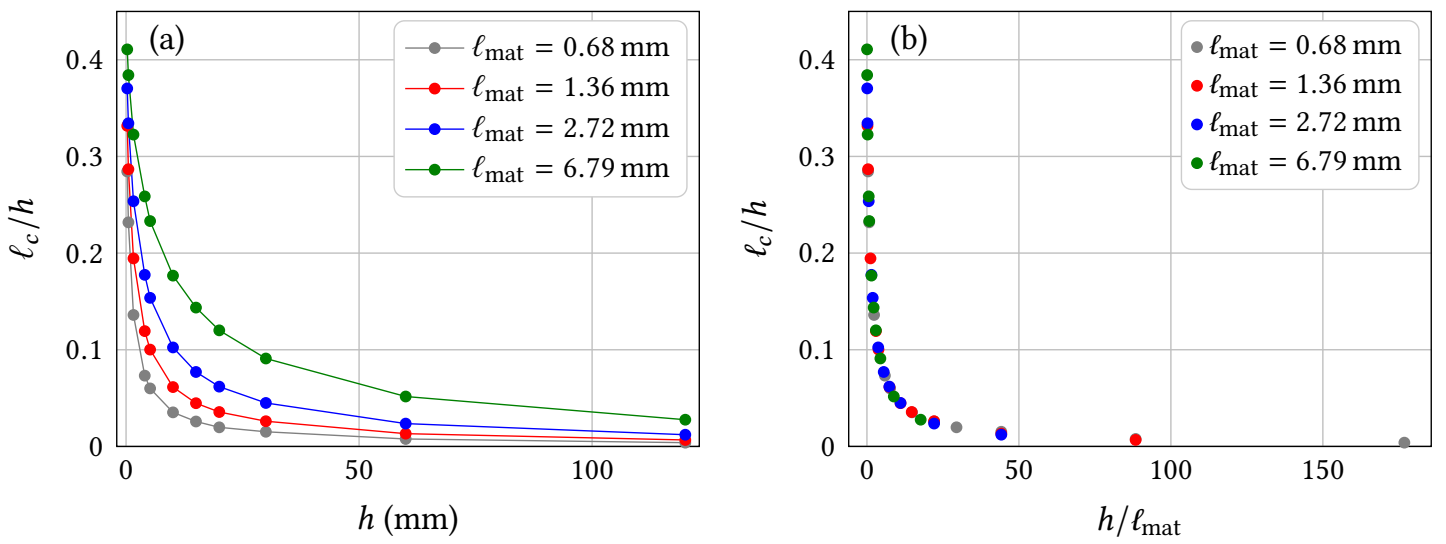

Figure 6 Initiation crack length to specimen height ratio for various $\left(\mathcal{G}_{c}, \sigma_{c}\right)$ couples corresponding to different material characteristic lengths $\ell_{\text {mat }}$ as a function of (a) the specimen size and (b) specimen height to material characteristic length ratio.

For a given specimen height, the same $\ell_{c} / h$ is obtained for different fracture parameter couples leading to the same material characteristic length. The initiation length to specimen height ratio decreases with increasing specimen height and for a fixed specimen height, the larger the material characteristic length, the larger the initiation length. Moreover, the initiation length to specimen height ratio as a function of the specimen height to material characteristic length ratio is independent of the material parameters and can thus be described by a master curve.

Figure 7 shows the maximum flexural stress to strength ratio as a function of either the specimen height or the specimen height to material characteristic length ratio. Once again, the same variation is obtained for different fracture parameter couples leading to the same material characteristic length. The maximum flexural stress to strength ratio decreases with increasing specimen height and for a fixed specimen height, the larger the material characteristic length, the larger the maximum flexural stress. The maximum flexural stress to strength ratio as a function of the specimen height to material characteristic length ratio is independent of the material properties so that it can also be described by a master curve.

The deterministic size effect of increasing failure stress with decreasing specimen size under bending can be explained by the interaction between the initiation length predicted by the CC and the sample dimensions. Note that even if the initiation length is related to the material characteristic length, it also depends on the specimen geometry. Therefore, the initiation length must be compared to both the specimen height and the material characteristic length to assess the size effect. The CC predicts a unique relation between $\ell_{c} / h$ and $h / \ell_{\text {mat }}$ that is monotonically 

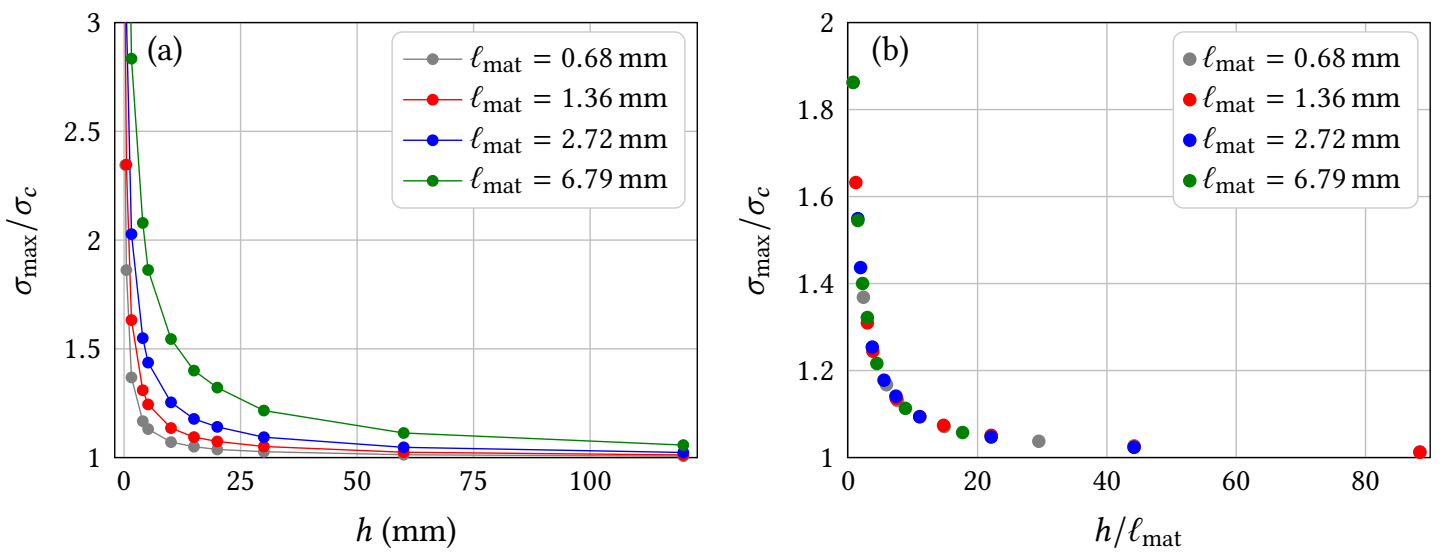

Figure 7 Maximum flexural stress to strength ratio for various $\left(\mathcal{G}_{c}, \sigma_{c}\right)$ couples corresponding to different material characteristic lengths $\ell_{\text {mat }}$ as a function of (a) the specimen size and (b) specimen height to material characteristic length ratio.

decreasing and tends towards 0 for large $h / \ell_{\text {mat }}$. In this case, the initiation length is sufficiently small so that the stress is higher than the strength on a short distance and the bending failure stress is close the tensile strength. Failure is thus mainly driven by the stress criterion in this case. The size effect arises from the interaction between the initiation length and the sample height. Indeed, in configurations for which the initiation length is not small with respect to the specimen height (i.e., for small $h / \ell_{\text {mat }}$ ratios), the stress exceeds the tensile strength over a sufficiently large distance so that the bending failure stress may be much larger than the tensile strength, as observed experimentally (Doitrand et al. 2020a). Failure is driven by both stress and energy criteria in this case, the energy condition becomes more and more dominant as $h / \ell_{\text {mat }} \rightarrow 0$.

\section{Post-processing procedure of four-point bending test}

In the previous section, we highlighted that both $\sigma_{\max } / \sigma_{c}$ and $\ell_{c} / h$, functions of $h / \ell_{\text {mat }}$, follow a master curve that does not depend on the material properties. The present section exploits these curves in order to provide a post-processing procedure for the determination of the material strength and fracture toughness based on four-point bending experiments.

\subsection{Analytical expression of the master curves}

The specimen height $h$ and the maximum flexural stress $\sigma_{\max }$ can be measured or obtained experimentally in four-point bending tests. We obtained a relation between $\sigma_{\max } / \sigma_{c}$ and $h / \ell_{\text {mat }}$ that does not depend on the tested material through the master curve (Figure 7). Therefore for given $\sigma_{\max }$ and $h$, we can adjust the material parameters so as to follow the master curve. This step could be done by interpolation of the calculated points forming the master curve (Cornetti et al. 2006). A more convenient approach consists in determining an analytical expression that reproduces the master curve, which we propose hereafter:

$$
\frac{\sigma_{\max }}{\sigma_{c}}=\frac{\left(h / \ell_{\text {mat }}\right)^{a}+1}{\left(h / \ell_{\text {mat }}\right)^{a}+b}
$$

with $a=0.884$ and $b=0.179$. This expression can be used in the range $h / \ell_{\text {mat }}>0.1$ for any material under linear elasticity and small deformation assumption. Given the relation between $\sigma_{\max }$ and $\ell_{c}$ (see Equation (3)), it yields

$$
\frac{\ell_{c}}{h}=\frac{1}{2} \frac{1-b}{\left(h / \ell_{\text {mat }}\right)^{a}+1} .
$$

Equations (4) and (5) can be used for any brittle materials with a linear elastic behavior. Figure 8(a) shows the proposed functions in classical and log-log space, which correctly reproduces the data obtained numerically to form the master curve. 

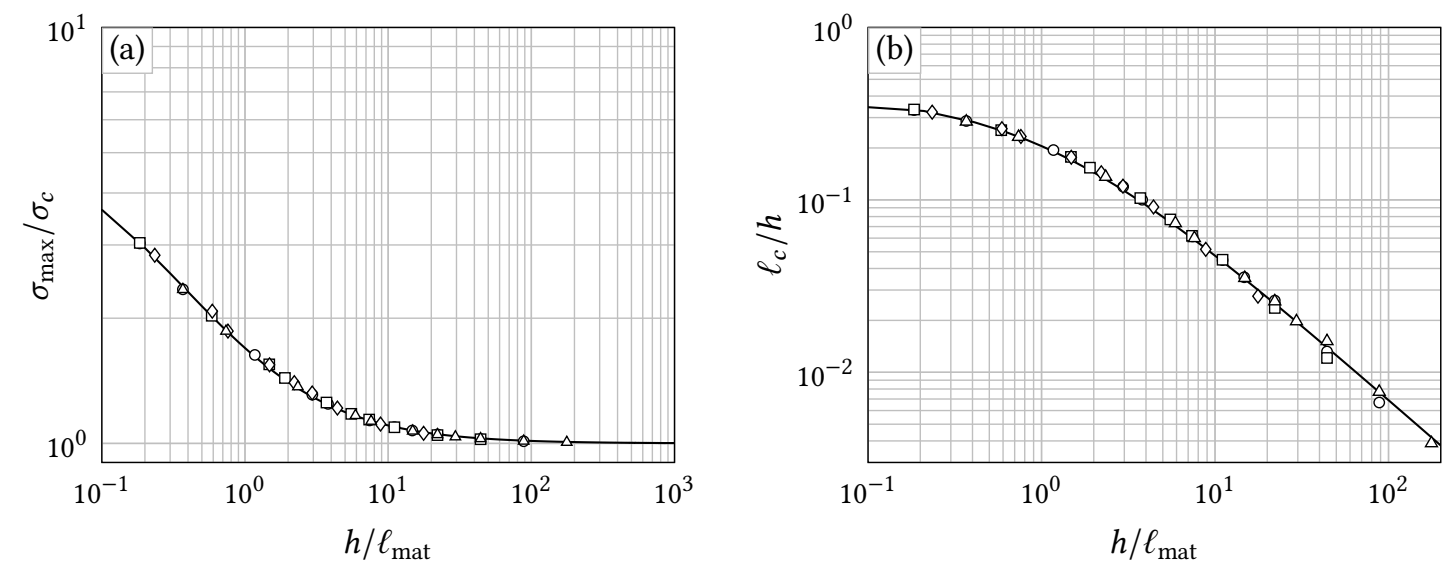

Figure 8 (a) Maximum flexural stress to strength ratio with interpolation using Equation (4) (solid line) and (b) initiation crack length to specimen height ratio with interpolation using Equation (5) (solid line) as a function of specimen height to material characteristic length ratio.

Rewriting the ratio $\sigma_{\max } / \sigma_{c}$ by replacing $\ell_{\text {mat }}$ by $E^{\prime} \mathcal{G}_{c} / \sigma_{c}^{2}$ yields

$$
\frac{\sigma_{\max }}{\sigma_{c}}=\frac{\left(\frac{h \sigma_{c}^{2}}{E^{\prime} \mathcal{G}_{c}}\right)^{a}+1}{\left(\frac{h \sigma_{c}^{2}}{E^{\prime} \mathcal{G}_{c}}\right)^{a}+b},
$$

which can also be rewritten as

$$
\sigma_{c}^{2 a+1}-\sigma_{\max } \sigma_{c}^{2 a}+\left(\frac{E^{\prime} \mathcal{G}_{c}}{h}\right)^{a} \sigma_{c}-\sigma_{\max } b\left(\frac{E^{\prime} \mathcal{G}_{c}}{h}\right)^{a}=0 .
$$

This equation can be solved in order to determine the fracture parameter $\mathcal{G}_{c}$ and $\sigma_{c}$. In next sections, we provide examples of the parameter determination in cases:

i) $\sigma_{c}$ is known,

ii) $\mathcal{G}_{c}$ is known,

iii) neither $\mathcal{G}_{c}$ nor $\sigma_{c}$ are known.

\subsection{Determination of the material fracture toughness $\mathcal{G}_{c}$}

We assume in this section that the only unknown material property is $\mathcal{G}_{c}$ (or $K_{I c}$ ). The Young's modulus and strength for the different gypsums are those given in Section 2. Rewritting Equation (7) yields

$$
\mathcal{G}_{c}=\frac{h \sigma_{c}^{2}}{E^{\prime}}\left(\frac{\sigma_{\max } b-\sigma_{c}}{\sigma_{c}-\sigma_{\max }}\right)^{-1 / a}
$$

which is an explicit expression of the quantities measured experimentally (specimen height and maximum flexural stress) and of the other material properties $\left(E^{\prime}\right.$ and $\left.\sigma_{c}\right)$. Using Equation (8), each tested specimen provides a value of $\mathcal{G}_{c}$. Therefore, the scattering obtained on the identified values is representative of the statistical scattering for a given specimen size, which mainly depends on the presence of macropores in the case of gypsum. The values obtained for the three shades of gypsum are shown as a function of the specimen height or the specimen density for $\mathcal{G}_{c}$ (Figure 9) or $K_{I c}$ (Figure 10) and the mean and standard deviation are given in Table 3.

$\begin{array}{lccc}\text { Material } & \sigma_{c}(\mathrm{MPa})(\text { fixed }) & \mathcal{G}_{c}\left(\mathrm{~J} / \mathrm{m}^{2}\right) \text { (identified) } & K_{I c}\left(\mathrm{MPa} \cdot \mathrm{m}^{1 / 2}\right) \text { (identified) } \\ \gamma \text {-gypsum } & 12 & 4.7 \pm 1.9 & 0.42 \pm 0.078 \\ \alpha \text {-gypsum } & 9.5 & 7.6 \pm 1.4 & 0.35 \pm 0.031 \\ \beta \text {-gypsum } & 2.7 & 3.0 \pm 2.2 & 0.1 \pm 0.029\end{array}$

Table 3 Identified fracture toughness $\mathcal{G}_{c}$ and critical energy release rate $K_{I c}$ mean and standard deviation for specified $\sigma_{c}$ values. 

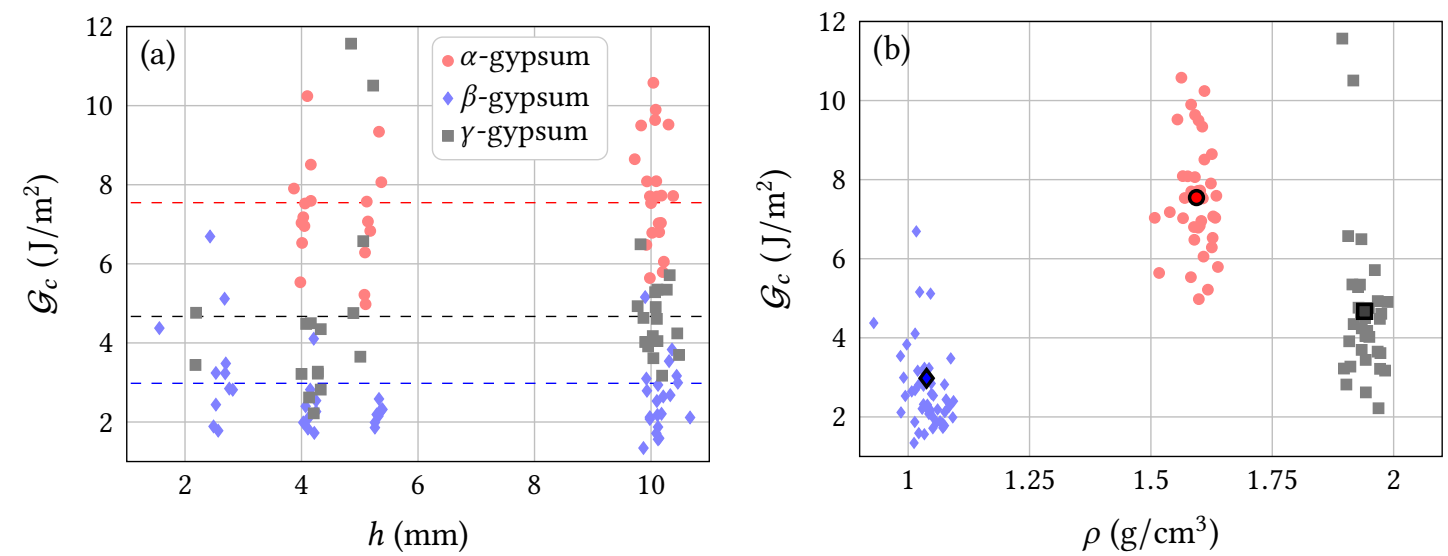

Figure 9 Fracture toughness $\mathcal{G}_{c}$ identified from experimental measurements of specimen height $h$ and maximum flexural stress $\sigma_{\max }$ on gypsum specimens assuming $\sigma_{c}=9.5 \mathrm{~J} / \mathrm{m}^{2}\left(\alpha\right.$-gypsum), $\sigma_{c}=2.7 \mathrm{~J} / \mathrm{m}^{2}(\beta$-gypsum) and $\sigma_{c}=12 \mathrm{~J} / \mathrm{m}^{2}$ ( $\gamma$-gypsum) as a function of specimen (a) height $h$ and (b) density $\rho$ : dark markers indicate mean values.
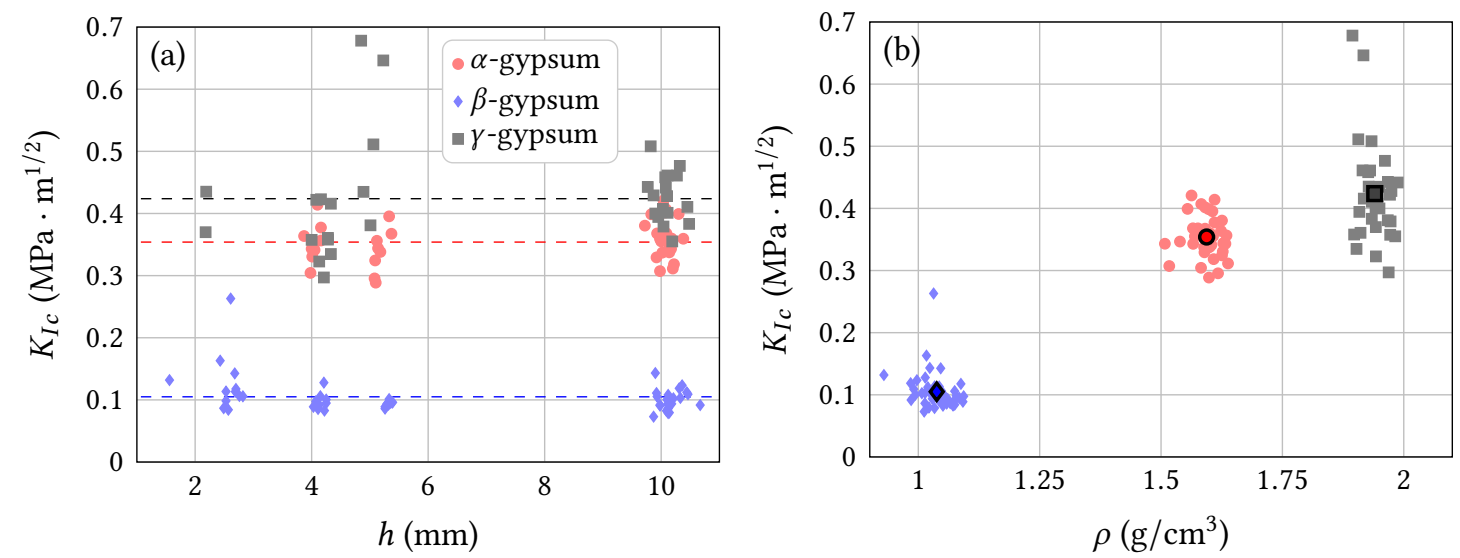

Figure 10 Critical stress intensity factor $K_{I c}$ identified from experimental measurements of specimen height $h$ and maximum flexural stress $\sigma_{\max }$ on gypsum specimens assuming $\sigma_{c}=9.5 \mathrm{~J} / \mathrm{m}^{2}$ ( $\alpha$-gypsum), $\sigma_{c}=2.7 \mathrm{~J} / \mathrm{m}^{2}$ ( $\beta$-gypsum) and $\sigma_{c}=12 \mathrm{~J} / \mathrm{m}^{2}$ ( $\gamma$-gypsum) as a function of specimen (a) height $h$ and (b) density $\rho$ : dark markers indicate mean values.

The computed mean values share the order of magnitude of existing ones (Meille and Garboczi 2001; Sanahuja et al. 2010; Meille 2001) recalled in Section 2. For specimens showing a large $h / \ell_{\text {mat }}$ ratio $\left(h / \ell_{\text {mat }}>20\right)$, failure is mainly driven by the stress condition. Therefore, the post-processing of the experiments provides a good estimate of the tensile strength. However, it is not expected to obtain an accurate value of the fracture toughness in this case even though for smaller $h / \ell_{\text {mat }}$ ratios, both the tensile strength and fracture toughness can be determined accurately.

\subsection{Determination of the tensile strength $\sigma_{c}$}

We assume in this section that the only unknown material property is the tensile strength $\sigma_{c}$. The Young's modulus and fracture toughness for the different gypsums are those given in Section 2. Contrary to the case for which only $\mathcal{G}_{c}$ is not known which provides an explicit solution, the determination of $\sigma_{c}$ requires solving Equation (7). This can be done numerically which provides a value of $\sigma_{c}$ for each tested specimens. The values obtained for the three shades of gypsum are shown as a function of the specimen height or the specimen density in Figure 11 and the mean and standard deviation are given in Table 4 .

\subsection{Joint determination of $\mathcal{G}_{c}$ and $\sigma_{c}$}

The last example concerns the case for which neither $\sigma_{c}$ nor $\mathcal{G}_{c}$ are known. It is possible to deduce simultaneously $\mathcal{G}_{c}$ and $\sigma_{c}$ based on a set of experimental results. Let us consider that $N$ measurements of the specimen height and maximum flexural stress $\left\{\left(\sigma_{\max }^{(i)}, h^{(i)}\right), i=1 . . N\right\}$ are 

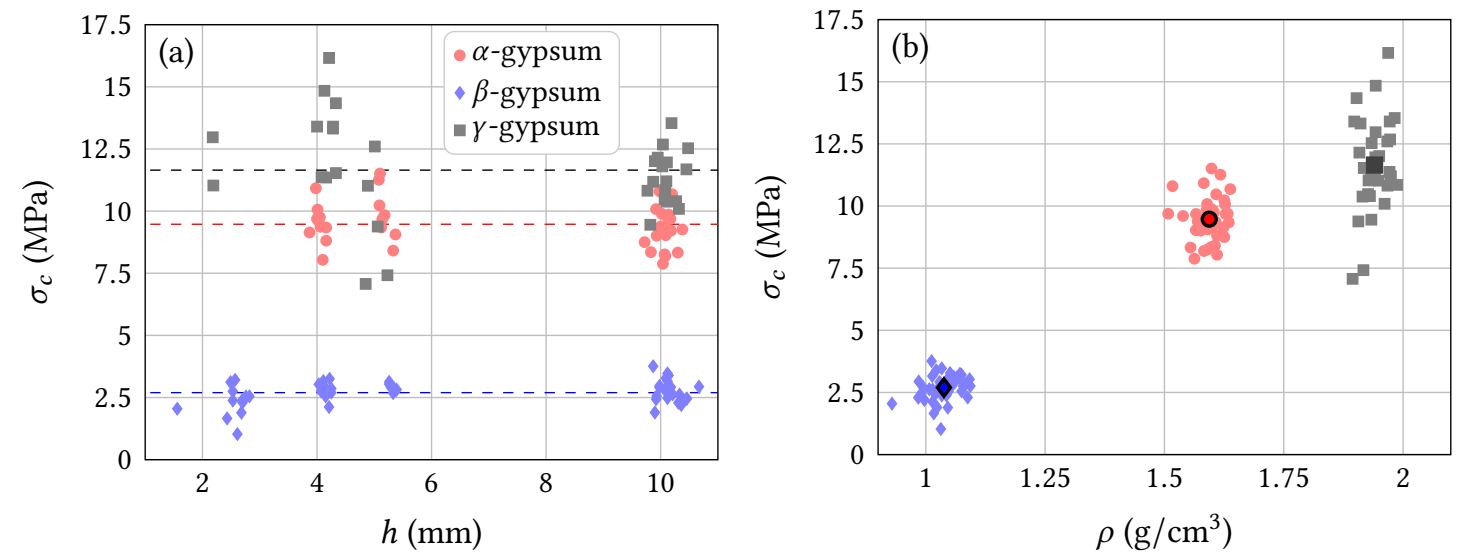

Figure 11 Strength $\sigma_{c}$ identified from experimental measurements of specimen height $h$ and maximum flexural stress $\sigma_{\max }$ on gypsum specimens assuming $\mathcal{G}_{c}=7.3 \mathrm{~J} / \mathrm{m}^{2}$ ( $\alpha$-gypsum), $\mathcal{G}_{c}=2.5 \mathrm{~J} / \mathrm{m}^{2}$ ( $\beta$-gypsum) and $\mathcal{G}_{c}=4 \mathrm{~J} / \mathrm{m}^{2}$ ( $\gamma$-gypsum) as a function of specimen (a) height $h$ and (b) density $\rho$ : dark markers indicate mean values.

Table 4 Identified strength $\sigma_{c}$ mean and standard deviation for given $\mathcal{G}_{c}$ values.

$\begin{array}{lcc}\text { Material } & \mathcal{G}_{c}\left(\mathrm{~J} / \mathrm{m}^{2}\right)(\text { fixed }) & \sigma_{c}(\mathrm{MPa}) \text { (identified) } \\ \gamma \text {-gypsum } & 4.0 & 11.6 \pm 1.9 \\ \alpha \text {-gypsum } & 7.3 & 9.5 \pm 0.86 \\ \beta \text {-gypsum } & 2.5 & 2.7 \pm 0.5\end{array}$

available. Based on Equation (7), we define the functions

$$
R^{(i)}\left(\sigma_{c}, \mathcal{G}_{c}\right)=\sigma_{c}^{2 a+1}-\sigma_{\max }^{(i)} \sigma_{c}^{2 a}+\left(\frac{E^{\prime} \mathcal{G}_{c}}{h^{(i)}}\right)^{a} \sigma_{c}-\sigma_{\max }^{(i)} b\left(\frac{E^{\prime} \mathcal{G}_{c}}{h^{(i)}}\right)^{a}
$$

which should be close to zero provided the fracture parameters are those of the studied material. Therefore, we seek the couple $\left(\sigma_{c}^{*}, \mathcal{G}_{c}^{*}\right)$ that minimizes the following residuals

$$
R\left(\sigma_{c}, \mathcal{G}_{c}\right)=\sum_{i=1}^{N}\left(h^{(i)} R^{(i)}\left(\sigma_{c}, \mathcal{G}_{c}\right)\right)^{2} .
$$

The residuals are weighted by the specimen height in order to balance the higher measurement uncertainty sensitivity for small specimens (see next section for more details). The minimization of the residuals is performed using a gradient descent algorithm. Figure 12(a) shows the residuals for $\alpha$-gypsum as a function of $\mathcal{G}_{c}$ and $\sigma_{c}$ as well as the obtained minimum (black star).
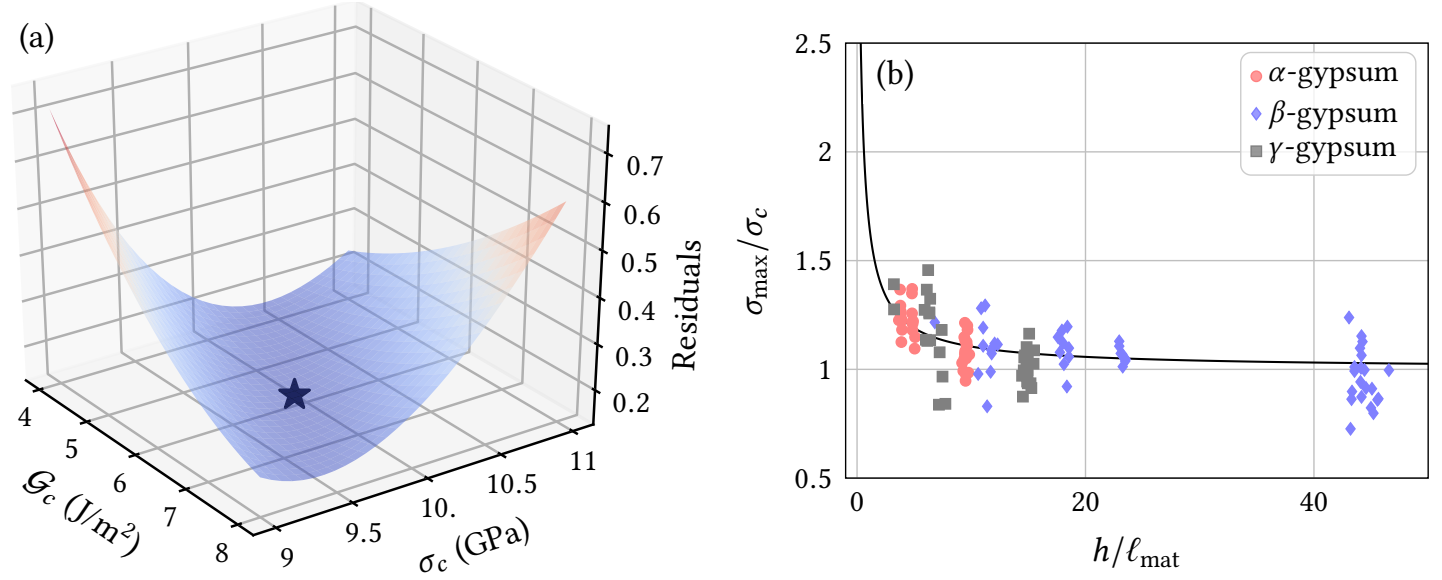

Figure 12 (a) Residuals as a function of strength $\sigma_{c}$ and fracture toughness $\mathcal{G}_{c}$ ( $\alpha$-gypsum) and (b) maximum flexural stress to strength ratio as a function of specimen height to material characteristic length ratio measured experimentally for the identified fracture properties; $\alpha$-gypsum: $\mathcal{G}_{c}^{\alpha}=6.15 \mathrm{~J} / \mathrm{m}^{2}, \sigma_{c}^{\alpha}=9.9 \mathrm{MPa}, \beta$-gypsum: $\mathcal{G}_{c}^{\beta}=0.62 \mathrm{~J} / \mathrm{m}^{2}, \sigma_{c}^{\beta}=3.3 \mathrm{MPa}, \gamma$-gypsum: $\mathcal{G}_{c}^{\gamma}=2.74 \mathrm{~J} / \mathrm{m}^{2}, \sigma_{c}^{\gamma}=12.7 \mathrm{MPa}$ corresponding to the residuals minimum. 
Figure 12(b) shows the maximum flexural stress to strength ratio as a function of specimen height to material characteristic length ratio for the identified values of $\mathcal{G}_{c}$ and $\sigma_{c}$ together with the master curve. The optimization process finally reverts to adjusting the experimental data to the master curve on Figure 12(b). The identified tensile strength and toughness corresponding to the residual minimum for each shade of gypsum are given in Table 5 .

The quality of strength and toughness identification depends on the specimen size related to the material characteristic length. Indeed, if only large enough $\left(h / \ell_{\text {mat }}>20\right)$ specimens are tested, it is expected that the maximum flexural stress is close to the material tensile strength, therefore the estimate of $\mathcal{G}_{c}$ may not be as accurate in this case as for smaller specimens, since for this configuration failure is mainly driven by the stress criterion.

$\begin{array}{ccccc}\text { Material } & \begin{array}{c}\text { identified } \mathcal{G}_{c} \\ \left(\mathrm{~J} / \mathrm{m}^{2}\right)\end{array} & \begin{array}{c}\text { identified } K_{I c} \\ \left(\mathrm{MPa} \cdot \mathrm{m}^{1 / 2}\right)\end{array} & \begin{array}{c}\text { identified } \sigma_{c} \\ (\mathrm{MPa})\end{array} & \begin{array}{c}\ell_{\text {mat }} \\ (\mathrm{mm})\end{array} \\ \gamma \text {-gypsum } & 2.74 & 0.33 & 12.7 & 0.68 \\ \alpha \text {-gypsum } & 6.15 & 0.32 & 9.9 & 1.06 \\ \beta \text {-gypsum } & 0.62 & 0.05 & 3.3 & 0.23\end{array}$

Table 5 Identified strength $\sigma_{c}$ and fracture toughness $\mathcal{G}_{c}$ based on four-point bending experiments.

The material characteristic lengths of the three shades of gypsum are between $\approx 0.2 \mathrm{~mm}$ and $1 \mathrm{~mm}$ (Table 5). It can be shown that the initiation crack length predicted by the CC is a fraction of the material characteristic length (Martin et al. 2018). Therefore, crack initiation may be influenced by a flaw which size lies in the same order of magnitude as the initiation crack length. It is the case for macropores, they are likely to induce premature failure provided they are sufficiently large and depending on their position in the specimen, which partly explains the scattering observed experimentally.
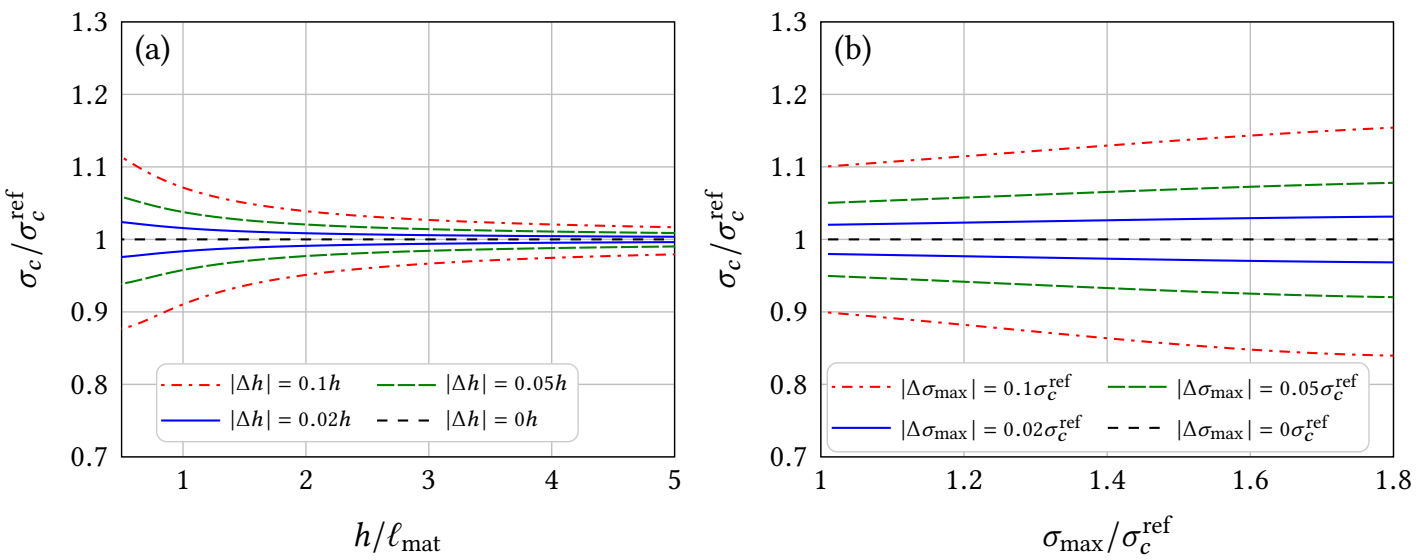

Figure 13 Uncertainty on determination of $\sigma_{c}$ as a function of the specimen size induced by various uncertainty levels on $\Delta h$ and $\Delta \sigma_{\max }$

\subsection{Measurement uncertainty influence on $\mathcal{G}_{c}$ and $\sigma_{c}$ identification}

We finally investigate the measurement uncertainty influence on $\mathcal{G}_{c}$ and $\sigma_{c}$ identification. The two quantities that are measured experimentally are the specimen height $h$ and the maximum flexural stress $\sigma_{\max }$. We denote $\Delta h$ and $\Delta \sigma_{\max }$ the measurement uncertainties respectively on the specimen height and the maximum flexural stress. We denote $\sigma_{c}^{\text {ref }}$ the identified strength without uncertainty measurement $\left(\Delta h=0 \mathrm{~mm}\right.$ and $\left.\Delta \sigma_{\max }=0 \mathrm{MPa}\right)$.

We first consider a measurement uncertainty on the specimen height and study its influence on the strength identification. Figure 13(a) shows the identified strength (taking into account the measurement uncertainty $\Delta h$ ) to reference strength ratios as a function of the specimen height to material characteristic length ratio. For specimens height larger than the material characteristic length, the relative uncertainty $\Delta h / h$ on the specimen size measurement induces an uncertainty 
on $\sigma_{c}$ identification $\Delta \sigma_{c} / \sigma_{c}^{\text {ref }}$ smaller than $\Delta h / h$. The influence of the measurement uncertainty on geometry is however larger for specimens height smaller than the material characteristic length.

We now consider a measurement uncertainty $\Delta \sigma_{\max }$ on the maximum flexural stress. Figure 13(b) shows the identified strength (taking into account the measurement uncertainty $\left.\Delta \sigma_{\max }\right)$ to reference strength ratios as a function of the maximum flexural stress to reference strength ratio. The uncertainty measurement on the maximum flexural stress $\Delta \sigma_{\max } / \sigma_{c}^{\text {ref }}$ induces an uncertainty on the determination of $\sigma_{c}$ approximately equal to $\Delta \sigma_{\max } / \sigma_{c}^{\text {ref }}$ for large specimen ( $h \gg \ell_{\text {mat }}$, corresponding to ratios $\sigma_{\max } / \sigma_{c}^{\text {ref }}$ close to 1 ) and increasing for smaller specimens ( $h \gg \ell_{\text {mat }}$, corresponding to ratios $\sigma_{\max } / \sigma_{c}^{\text {ref }}$ larger than 1 ).

\section{Conclusion}

The maximum flexural stress at failure under four-point bending, sometimes called flexural strength, cannot be considered as an intrinsic material property because of the well-known size effect leading to increasing maximum flexural stress with decreasing specimen size.

This size effect can be reproduced using the $\mathrm{CC}$ which allows the prediction of the failure force (and hence the maximum flexural stress) and the initiation crack length for given specimen geometry and material properties. The initiation length tends to a constant value for large enough specimens compared to the material characteristic length (failure driven by the stress criterion), whereas it tends to half the specimen height when the specimen height tends towards $o$ (failure driven by the energy criterion). For intermediate specimen heights, failure is driven by both stress and energy conditions and thus depends on both the material tensile strength and fracture toughness. The maximum flexural stress tends to the material tensile strength for specimens large enough compared to the material characteristic length, Therefore, according to the CC, measurements of the flexural strength can only be considered as a material parameter (actually, the tensile strength) for sufficiently large specimens.

We show that regardless of the material under investigation (under the assumption of linear elasticity), the maximum flexural stress to strength ratio variation as a function of the specimen height to material characteristic length ratio follows a master curve, which can be described by an analytical function involving two parameters. Based on this relationship, we establish a procedure for the determination of the material tensile strength and fracture toughness which can be employed for the post-processing of four-point bending experiments that only requires the measurement of the specimen height $h$ and the failure force $F_{c}$ in order to calculate the maximum flexural stress $\sigma_{\max }$.

\section{Acknowledgement}

We thank the students at INSA de Lyon who participated in the experimental part of this work: K. Lionti, A. Viguier, M. Vincent, C. Willer and I. Tams.

\section{Supplementary material}

The supplementary material is available at the following link: 10.5281/zenodo.4467389. It contains the data provided in the appendix (specimen dimensions, density, failure force and failure stress for the three studied shades of gypsum). 


\section{A Appendix}

\begin{tabular}{|c|c|c|c|c|c|c|c|c|c|c|}
\hline Specimen $\alpha \#$ & 1 & 2 & 3 & 4 & 5 & 6 & 7 & 8 & 9 & 10 \\
\hline$h(\mathrm{~mm})$ & 4.03 & 4.05 & 4.16 & 4.16 & 3.98 & 4.00 & 4.10 & 4.01 & 3.87 & 4.06 \\
\hline$t(\mathrm{~mm})$ & 3.10 & 3.07 & 3.00 & 2.99 & 3.06 & 3.01 & 3.03 & 2.96 & 3.12 & 3.02 \\
\hline$\rho\left(\mathrm{g} / \mathrm{cm}^{3}\right)$ & 1.53 & 1.6 & 1.63 & 1.61 & 1.58 & 1.63 & 1.61 & 1.62 & 1.62 & 1.60 \\
\hline$F_{c}(\mathrm{~N})$ & 16.61 & 16.76 & 16.74 & 16.09 & 17.43 & 16.00 & 15.08 & 16.19 & 15.07 & 16.15 \\
\hline$\sigma_{\max }(\mathrm{MPa})$ & 12.37 & 12.48 & 12.09 & 11.66 & 13.48 & 12.46 & 11.1 & 12.75 & 12.09 & 12.16 \\
\hline Specimen $\alpha \#$ & 11 & 12 & 13 & 14 & 15 & 16 & 17 & 18 & 19 & 20 \\
\hline$h(\mathrm{~mm})$ & 5.33 & 5.18 & 5.10 & 5.12 & 5.08 & 5.14 & 5.09 & 5.37 & 9.83 & 10.17 \\
\hline$t(\mathrm{~mm})$ & 10.32 & 10.35 & 10.29 & 9.85 & 10.49 & 10.25 & 10.1 & 10.13 & 10.23 & 10.63 \\
\hline$\rho\left(\mathrm{g} / \mathrm{cm}^{3}\right)$ & 1.60 & 1.60 & 1.59 & 1.60 & 1.61 & 1.62 & 1.62 & 1.59 & 1.59 & 1.5 \\
\hline$F_{c}(\mathrm{~N})$ & 34.91 & 36.88 & 39.86 & 33.15 & 39.70 & 35.61 & 35.77 & 36.47 & 106.7 & 132.6 \\
\hline$\sigma_{\max }(\mathrm{MPa})$ & 10.8 & 12.05 & 13.51 & 11.65 & 13.3 & 11.93 & 12.4 & 11.33 & 9.79 & 10.94 \\
\hline Specimen $\alpha \#$ & 21 & 22 & 23 & 24 & 25 & 26 & 27 & 28 & 29 & 30 \\
\hline$h(\mathrm{~mm})$ & 9.72 & 10.00 & 9.98 & 10.08 & 10.02 & 9.92 & 10.38 & 10.14 & 9.93 & 10.1 \\
\hline$t(\mathrm{~mm})$ & 10.08 & 10.30 & 10.56 & 10.18 & 10.48 & 10.23 & 9.95 & 10.15 & 10.29 & 10.12 \\
\hline$\rho\left(\mathrm{g} / \mathrm{cm}^{3}\right)$ & 1.62 & 1.56 & 1.51 & 1.58 & 1.59 & 1.58 & 1.59 & 1.58 & 1.57 & 1.58 \\
\hline$F_{c}(\mathrm{~N})$ & 106.6 & 121.3 & 138.8 & 109.7 & 129.3 & 125.6 & 124.5 & 127.7 & 115.8 & 120.5 \\
\hline$\sigma_{\max }(\mathrm{MPa})$ & 10.15 & 10.69 & 11.97 & 9.62 & 11.15 & 11.32 & 10.53 & 11.1 & 10.35 & 10.59 \\
\hline Specimen $\alpha \#$ & 31 & 32 & 33 & 34 & 35 & 36 & 37 & 38 & 39 & \\
\hline$h(\mathrm{~mm})$ & 10.07 & 10.09 & 10.18 & 10.04 & 10.22 & 10.13 & 10.2 & 10.3 & 9.98 & \\
\hline$t(\mathrm{~mm})$ & 9.87 & 10.03 & 10.16 & 10.09 & 10.22 & 10.15 & 10.09 & 10.18 & 10.35 & \\
\hline$\rho\left(\mathrm{g} / \mathrm{cm}^{3}\right)$ & 1.59 & 1.56 & 1.6 & 1.56 & 1.6 & 1.56 & 1.63 & 1.55 & 1.59 & \\
\hline$F_{c}(\mathrm{~N})$ & 106.7 & 116.6 & 121.9 & 104.7 & 137.2 & 125.6 & 137.1 & 115.6 & 120.1 & \\
\hline$\sigma_{\max }(\mathrm{MPa})$ & 9.67 & 10.36 & 10.5 & 9.34 & 11.66 & 10.94 & 11.85 & 9.71 & 10.57 & \\
\hline
\end{tabular}

Table A.1 Dimensions, failure force $F_{c}$ and stress $\sigma_{\max }$ corresponding to $\alpha$-gypsum specimens for $L_{\text {span }}=35 \mathrm{~mm}$ and $\ell_{\text {span }}=10 \mathrm{~mm}$ (specimens $\alpha 1$ to $\alpha 10$ ) or $L_{\text {span }}=90.5 \mathrm{~mm}, \ell_{\text {span }}=30 \mathrm{~mm}$ (specimens $\alpha 11$ to $\left.\alpha 39\right)$ distances between the lower and upper spans.

$\begin{array}{lcccccccccc}\text { Specimen } \beta \# & 1 & 2 & 3 & 4 & 5 & 6 & 7 & 8 & 9 & 10 \\ h(\mathrm{~mm}) & 1.56 & 2.57 & 2.82 & 2.76 & 2.53 & 2.61 & 2.7 & 2.69 & 2.68 & 2.49 \\ t(\mathrm{~mm}) & 6.88 & 7.05 & 7.74 & 7.07 & 7.17 & 7.34 & 6.81 & 7.9 & 7.79 & 7.34 \\ \rho\left(\mathrm{g} / \mathrm{cm}^{3}\right) & 0.92 & 1.07 & 1.02 & 1.04 & 1.03 & 1.03 & 1.08 & 1.04 & 1.04 & 1.06 \\ F_{c}(\mathrm{~N}) & 1.78 & 5.27 & 6.00 & 5.27 & 4.45 & 3.63 & 4.66 & 5.45 & 4.84 & 5.10 \\ \sigma_{\max }(\mathrm{MPa}) & 3.99 & 4.24 & 3.65 & 3.67 & 3.63 & 2.72 & 3.52 & 3.57 & 3.24 & 4.20 \\ \text { Specimen } \beta \# & 11 & 12 & 13 & 14 & 15 & 16 & 17 & 18 & 19 & 20 \\ h(\mathrm{~mm}) & 2.53 & 2.43 & 4.07 & 4.03 & 4.11 & 4.22 & 4.25 & 4.13 & 4.21 & 4.25 \\ t(\mathrm{~mm}) & 6.61 & 6.39 & 2.95 & 2.90 & 2.90 & 2.93 & 2.89 & 2.91 & 2.99 & 2.90 \\ \rho\left(\mathrm{g} / \mathrm{cm}^{3}\right) & 1.07 & 1.01 & 1.09 & 1.09 & 1.07 & 1.07 & 1.05 & 1.07 & 1.01 & 1.08 \\ F_{c}(\mathrm{~N}) & 4.41 & 3.23 & 4.61 & 4.73 & 5.05 & 5.46 & 4.83 & 4.87 & 4.27 & 5.03 \\ \sigma_{\max }(\mathrm{MPa}) & 3.91 & 3.21 & 3.53 & 3.76 & 3.86 & 3.92 & 3.47 & 3.68 & 3.02 & 3.6 \\ \text { Specimen } \beta \# & 21 & 22 & 23 & 24 & 25 & 26 & 27 & 28 & 29 & 30 \\ h(\mathrm{~mm}) & 4.15 & 5.38 & 5.32 & 5.26 & 5.33 & 5.39 & 5.26 & 5.29 & 5.35 & 10.21 \\ t(\mathrm{~mm}) & 2.95 & 10.22 & 10.1 & 10.21 & 10.27 & 9.75 & 10.1 & 10.28 & 9.97 & 10.67 \\ \rho\left(\mathrm{g} / \mathrm{cm}^{3}\right) & 1.07 & 1.03 & 1.04 & 1.05 & 1.04 & 1.03 & 1.05 & 1.06 & 1.03 & 1.01 \\ F_{c}(\mathrm{~N}) & 4.55 & 11.10 & 11.05 & 11.53 & 10.68 & 10.71 & 11.18 & 11.16 & 10.89 & 36.78 \\ \sigma_{\max }(\mathrm{MPa}) & 3.35 & 3.40 & 3.50 & 3.70 & 3.32 & 3.43 & 3.63 & 3.52 & 3.46 & 3.00\end{array}$




$\begin{array}{lcccccccccc}\text { Specimen } \beta \# & 31 & 32 & 33 & 34 & 35 & 36 & 37 & 38 & 39 & 40 \\ h(\mathrm{~mm}) & 10.1 & 10.36 & 9.93 & 10.12 & 9.92 & 10.33 & 10.44 & 10.14 & 10.09 & 10.11 \\ t(\mathrm{~mm}) & 10.98 & 10.42 & 10.6 & 10.57 & 10.32 & 10.98 & 10.48 & 10.36 & 10.69 & 10.43 \\ \rho\left(\mathrm{g} / \mathrm{cm}^{3}\right) & 0.99 & 1.00 & 1.03 & 1.04 & 1.03 & 1.01 & 1.02 & 1.02 & 1.05 & 1.05 \\ F_{c}(\mathrm{~N}) & 38.17 & 32.29 & 33.94 & 34.18 & 31.69 & 38.60 & 35.52 & 43.43 & 43.19 & 38.82 \\ \sigma_{\max }(\mathrm{MPa}) & 3.09 & 2.62 & 2.95 & 2.87 & 2.83 & 2.99 & 2.82 & 3.70 & 3.60 & 3.30 \\ \text { Specimen } \beta \# & 41 & 42 & 43 & 44 & 45 & 46 & 47 & 48 & 49 & 50 \\ h(\mathrm{~mm}) & 9.98 & 9.98 & 10.12 & 10.18 & 9.87 & 10.67 & 10.12 & 10.31 & 9.9 & 10.46 \\ t(\mathrm{~mm}) & 10.46 & 10.44 & 10.45 & 10.34 & 10.79 & 10.57 & 10.47 & 10.73 & 10.84 & 10.66 \\ \rho\left(\mathrm{g} / \mathrm{cm}^{3}\right) & 1.04 & 1.05 & 1.01 & 1.03 & 1.01 & 0.99 & 1.03 & 0.98 & 1.02 & 0.99 \\ F_{c}(\mathrm{~N}) & 38.04 & 37.31 & 41.20 & 38.65 & 47.07 & 43.35 & 44.70 & 33.94 & 27.91 & 36.47 \\ \sigma_{\max }(\mathrm{MPa}) & 3.32 & 3.26 & 3.49 & 3.27 & 4.06 & 3.27 & 3.78 & 2.70 & 2.38 & 2.84\end{array}$

Table A.2 Dimensions, failure force $F_{c}$ and stress $\sigma_{\max }$ corresponding to $\beta$-gypsum specimens for $L_{\mathrm{span}}=35 \mathrm{~mm}$ and $\ell_{\text {span }}=10 \mathrm{~mm}$ (specimens $\beta 1$ to $\beta 21$ ) or $L_{\text {span }}=90.5 \mathrm{~mm}, \ell_{\text {span }}=30 \mathrm{~mm}$ (specimens $\beta 22$ to $\beta 50$ ) distances between the lower and upper spans.

\begin{tabular}{|c|c|c|c|c|c|c|c|c|c|}
\hline Specimen $\gamma \#$ & 1 & 2 & 3 & 4 & 5 & 6 & 7 & 8 & 9 \\
\hline$h(\mathrm{~mm})$ & 2.19 & 2.18 & 4.16 & 4.00 & 4.28 & 4.21 & 4.13 & 4.08 & 4.33 \\
\hline$t(\mathrm{~mm})$ & 7.07 & 9.64 & 3.04 & 3.03 & 2.97 & 2.99 & 2.99 & 2.92 & 3.04 \\
\hline$\rho\left(\mathrm{g} / \mathrm{cm}^{3}\right)$ & 1.92 & 1.94 & 1.94 & 1.97 & 1.89 & 1.96 & 1.94 & 1.97 & 1.9 \\
\hline$F_{c}(\mathrm{~N})$ & 14.65 & 21.59 & 20.15 & 20.91 & 23.25 & 19.39 & 31.37 & 18.70 & 25.57 \\
\hline$\sigma_{\max }(\mathrm{MPa})$ & 16.2 & 17.67 & 14.36 & 16.17 & 16.02 & 18.49 & 17.35 & 14.42 & 16.82 \\
\hline Specimen $\gamma \#$ & 10 & 11 & 12 & 13 & 14 & 15 & 16 & 17 & 18 \\
\hline$h(\mathrm{~mm})$ & 4.28 & 4.33 & 5.06 & 5.01 & 4.85 & 4.89 & 5.23 & 10.45 & 9.82 \\
\hline$t(\mathrm{~mm})$ & 3.07 & 3.05 & 10.21 & 10.13 & 10.37 & 9.93 & 10.26 & 10.01 & 10.08 \\
\hline$\rho\left(\mathrm{g} / \mathrm{cm}^{3}\right)$ & 1.91 & 1.91 & 1.9 & 1.96 & 1.89 & 1.94 & 1.91 & 1.93 & 1.93 \\
\hline$F_{c}(\mathrm{~N})$ & 23.94 & 21.97 & 35.37 & 42.03 & 28.59 & 35.84 & 33.05 & 156.95 & 118.99 \\
\hline$\sigma_{\max }(\mathrm{MPa})$ & 15.96 & 14.4 & 12.27 & 15.00 & 10.63 & 13.69 & 10.68 & 13.03 & 11.10 \\
\hline Specimen $\gamma \#$ & 19 & 20 & 21 & 22 & 23 & 24 & 25 & 26 & 27 \\
\hline$h(\mathrm{~mm})$ & 10.1 & 9.9 & 10.11 & 10.07 & 10.32 & 10.19 & 10.27 & 10.08 & 10.04 \\
\hline$t(\mathrm{~mm})$ & 9.50 & 10.09 & 10.08 & 10.06 & 10.05 & 10.02 & 9.85 & 9.75 & 10.05 \\
\hline$\rho\left(\mathrm{g} / \mathrm{cm}^{3}\right)$ & 1.97 & 1.94 & 1.91 & 1.92 & 1.96 & 1.98 & 1.93 & 1.98 & 1.97 \\
\hline$F_{c}(\mathrm{~N})$ & 134.89 & 146.02 & 134.95 & 134.78 & 136.96 & 169.50 & 136.10 & 134.45 & 156.30 \\
\hline$\sigma_{\max }(\mathrm{MPa})$ & 12.63 & 13.40 & 11.88 & 11.99 & 11.61 & 14.78 & 11.88 & 12.31 & 14.00 \\
\hline Specimen $\gamma \#$ & 28 & 29 & 30 & 31 & 32 & 33 & & & \\
\hline$h(\mathrm{~mm})$ & 9.95 & 9.87 & 9.77 & 10.48 & 10.11 & 10.03 & & & \\
\hline$t(\mathrm{~mm})$ & 10.11 & 10.12 & 10.15 & 10.03 & 10.05 & 10.04 & & & \\
\hline$\rho\left(\mathrm{g} / \mathrm{cm}^{3}\right)$ & 1.90 & 1.93 & 1.96 & 1.93 & 1.94 & 1.94 & & & \\
\hline$F_{c}(\mathrm{~N})$ & 149.08 & 137.36 & 131.61 & 167.67 & 150.84 & 146.84 & & & \\
\hline$\sigma_{\max }(\mathrm{MPa})$ & 13.51 & 12.64 & 12.32 & 13.81 & 13.32 & 13.19 & & & \\
\hline
\end{tabular}

Table A.3 Dimensions, failure force $F_{c}$ and stress $\sigma_{\max }$ corresponding to $\gamma$-gypsum for $L_{\mathrm{span}}=35 \mathrm{~mm}$ and $\ell_{\text {span }}=$ $10 \mathrm{~mm}$ (specimens $\gamma 1$ to $\gamma 11$ ) or $L_{\text {span }}=90.5 \mathrm{~mm}, \ell_{\text {span }}=30 \mathrm{~mm}$ (specimens $\gamma 12$ to $\gamma 33$ ) distances between the lower and upper spans. 


\section{References}

Adrien, J., S. Meille, S. Tadier, E. Maire, and L. Sasaki (2016). In-situ X-ray tomographic monitoring of gypsum plaster setting. Cement and Concrete Research 82:107-116. [DOI], [OAI].

Bažant, Z. (1984). Size effect in blunt fracture: concrete, rock, metal. ASCE fournal of Engineering Mechanics 110:518-35. [DOI].

Bažant, Z. and P. Pfeiffer (1987). Determination of fracture energy from size effect and brittleness number. ACI Materials fournal 84:463-480. [DOI].

Bažant, Z. and J. Planas (1998). Fracture and size effect in concrete and other quasibrittle materials. Boca Raton: CRC Press. [DOI].

Bažant, Z. and Y. Xi (1991). Statistical size effect in quasi-brittle structures: II. Nonlocal theory. ASCE Journal of Engineering Mechanics 117 (11):2623-2640. [DOI].

Bažant, Z. (1999). Size effect on structural strength: a review. Archive of Applied Mechanics $69(9-10): 703-725$. [DOI].

Bermejo, R. and R. Danzer (2014). Mechanical Characterization of Ceramics: Designing with Brittle Materials. Comprehensive Hard Materials 2:285-298. [DOI].

Carpinteri, A., P. Cornetti, and A. Sapora (2011). Brittle failures at rounded V-notches: a finite fracture mechanics approach. International fournal of Fracture 172:1-8. [DOI].

Cornetti, P., N. Pugno, A. Carpinteri, and D. Taylor (2006). Finite fracture mechanics: A coupled stress and energy failure criterion. Engineering Fracture Mechanics 73:2021-2033. [DOI].

Cornetti, P. and A. Sapora (2019). Penny-shaped cracks by Finite Fracture Mechanics. International fournal of Fracture 219:153-159. [DOI].

Cornetti, P., A. Sapora, and A. Carpinteri (2013). Mode mixity and size effect in V-notched structures. International fournal of Solids and Structures 50 (10):1562-1582. [DOI].

Doitrand, A., R. Estevez, and D. Leguillon (2019). Experimental characterization and numerical modeling of crack initiation in rhombus hole PMMA specimens under compression. European fournal of Mechanics - A/Solids 76:290-299. [DOI], [OAI].

Doitrand, A., R. Henry, J. Chevalier, and S. Meille (2020a). Revisiting the strength of micron-scale ceramic platelets. Fournal of the American Ceramic Society 103:6991-7000. [DOI], [OAI].

Doitrand, A., R. Henry, I. Zacharie-Aubrun, G. J.M., and S. Meille (202ob). $\mathrm{UO}_{2}$ micron scale specimen fracture : Parameter identification and influence of porosities. Theoretical and Applied Fracture Mechanics 108:102665. [DOI], [OAI].

Doitrand, A., E. Martin, and D. Leguillon (2020c). Numerical implementation of the coupled criterion: Matched asymptotic and full finite element approaches. Finite Element in Analysis and Design 168:103344. [DOI], [OAI].

Doitrand, A. and A. Sapora (2020). Nonlinear implementation of Finite Fracture Mechanics: A case study on notched Brazilian disk samples. International fournal of Non-Linear Mechanics 119:103245. [DOI], [OAI].

Feilden, E., T. Giovannini, N. Ni, C. Ferraro, E. Saiz, and L. Vandeperre (2017). Micromechanical strength of $\mathrm{Al}_{2} \mathrm{O}_{3}$ platelets. Scripta Materialia 131:55-58. [DOI].

Gallo, P. and A. Sapora (2020). Brittle failure of nanoscale notched silicon cantilevers: a finite fracture mechanics approach. Applied Sciences 10 (5):1640. [DOI].

García, I. G., B. J. Carter, A. R. Ingraffea, and V. Mantič (2016). A numerical study of transverse cracking in cross-ply laminates by 3D finite fracture mechanics. Composites Part B 95:475-487. [DOI].

García, I. G., V. Mantič, and A. Blázquez (2018). The effect of residual thermal stresses on transverse cracking in cross-ply laminates: an application of the coupled criterion of the finite fracture mechanics. International fournal of Fracture 211:61-74. [DOI].

García, I., J. Justo, A. Simon, and V. Mantič (2019). Experimental study of the size effect on transverse cracking in cross-ply laminates and comparison with the main theoretical models. Mechanics of Materials 128:24-37. [DOI].

Leguillon, D. (2002). Strength or toughness? A criterion for crack onset at a notch. European fournal of Mechanics - A/Solids 21 (1):61-72. [DOI].

Leguillon, D., E. Martin, and M. Lafarie-Frenot (2015). Flexural vs. tensile strength in brittle materials. Comptes Rendus Mécanique 343 (4):275-281. [DOI], [OAI]. 
Leguillon, D., E. Martin, O. Seveček, and R. Bermejo (2018). What is the tensile strength of a ceramic to be used in numerical models for predicting crack initiation? International fournal of Fracture 212 (1):89-103. [DOI], [OAI].

Leguillon, D., D. Quesada, C. Putot, and E. Martin (2007). Size effects for crack initiation at blunt notches or cavities. Engineering Fracture Mechanics 74:2420-2436. [DOI].

$\mathrm{Lu}, \mathrm{C}$., R. Danzer, and F. Fischer (2004). Scaling of fracture strength in ZnO: Effects of pore/grain size interaction and porosity. Journal of the European Ceramic Society 24:3643-3651. [DOI].

Martin, E., D. Leguillon, and N. Carrère (2012). A coupled strength and toughness criterion for the prediction of the open hole tensile strength of a composite plate. International fournal of Solids and Structures 49 (26):3915-3922. [DOI], [OAI].

Martin, E., D. Leguillon, O. Seveček, and R. Bermejo (2018). Understanding the tensile strength of ceramics in the presence of small critical flaws. Engineering Fracture Mechanics 201:167-175. [DOI], [OAI].

Meille, S. (2001). Étude du comportement mécanique du plâtre pris en relation avec sa microstructure. $\mathrm{PhD}$ thesis. Institut National des Sciences Appliquées de Lyon. [OAI].

Meille, S. and E. Garboczi (2001). Linear elastic properties of 2D and 3D models of porous materials made from elongated objects. Modelling and Simulation in Materials Science and Engineering 9:371-390. [DOI], [OAI].

Parvizi, A., K. Garrett, and J. Bailey (1978). Constrained cracking in glass fibre-reinforced epoxy cross-ply laminates. Journal of Materials Science 13 (1):195-201. [DOI].

Sanahuja, J., L. Dormieux, S. Meille, C. Hellmich, and A. Fritsch (2010). Micromechanical explanation of elasticity and strength of gypsum: from elongated anisotropic crystals to isotropic porous polycrystals. fournal of Engineering Mechanics 136:239-253. [DOI], [OAI].

Weibull, W. (1939). The Phenomenon of Rupture in Solids. Handlingar / Ingeniörsvetenskapsakademien. Generalstabena Litografiska Anstalts Forlag.

Weibull, W. (1949). A Statistical Representation of Fatigue Failures in Solids. Acta Polytechnica. Henrik Lindståhl.

Weibull, W. (1951). A statistical distribution function of wide applicability. ASME fournal of Applied Mechanics 18:293-297. [OAI].

Weißgraeber, P., D. Leguillon, and W. Becker (2016). A review of Finite Fracture Mechanics: crack initiation at singular and non-singular stress raisers. Archive of Applied Mechanics $86(1-2): 375-401$. [DOI], [OAI].

Open Access This article is licensed under a Creative Commons Attribution 4.o International License,

which permits use, sharing, adaptation, distribution and reproduction in any medium or format, as long

as you give appropriate credit to the original author(s) and the source, provide a link to the Creative Commons license, and indicate if changes were made. The images or other third party material in this article are included in the article's Creative Commons license, unless indicated otherwise in a credit line to the material. If material is not included in the article's Creative Commons license and your intended use is not permitted by statutory regulation or exceeds the permitted use, you will need to obtain permission directly from the authors-the copyright holder. To view a copy of this license, visit creativecommons.org/licenses/by/4.o.

Authors' contributions Aurélien Doitrand: conceptualization, numerical investigation, writing original draft. Ronan Henry: conceptualization, numerical investigation, review and editing. Sylvain Meille: conceptualization, experimental investigation, review and editing.

Ethics approval and consent to participate Not applicable.

Consent for publication Not applicable.

Competing interests The authors declare that they have no competing interests.

Journal's Note JTCAM remains neutral with regard to the content of the publication and institutional affiliations. 